\title{
Outros domínios pedagógicos: a mídia ensinando sobre a mesmidade e a alteridade
}

\begin{abstract}
Fernanda de Camargo Machado* Márcia Lise Lunardi-Lazzarin**

\section{Resumo}

Este estudo tem como propósito problematizar o discurso da publicidade e seus efeitos de verdade no circuito contemporâneo. Nessa perspectiva, analisa como o enredo discursivo de um determinado anúncio de televisão narra, dissemina e, nessa relação, ensina sobre a mesmidade e a alteridade. Em outras palavras, como se delineiam as relações de poder e saber implicadas na produção da identidade e da diferença. Ao inscrever-se no campo dos Estudos Culturais em Educação, em sua matriz pós-estruturalista, o presente estudo busca, na produção filosófica de Michel Foucault, as noções de discurso, verdade e poder como ferramentas para empreender uma análise cultural da produção do outro e do mesmo no contexto examinado. É importante destacar que esse debate não pretende atribuir um juízo de valor à propaganda analisada. Sua intenção principal é problematizar o caráter produtivo e pedagógico do discurso publicitário, bem como seus efeitos de sentido, entre eles, a significação das diferenças como barreiras à igualdade.
\end{abstract}

Palavras-chave: Discurso Publicitário. Mesmidade. Alteridade.

\section{Other pedagogical grounds: media teaching about equality and alterity}

\begin{abstract}
This study aims to discuss the discourse of advertising and its effects of truth in contemporary circuit. From this perspective, looks like the plot of a particular discursive television ad tells, disseminates, and in that respect, teaches about sameness and otherness. In other words, how to delineate the relationships of power and knowledge involved in the production of identity and difference. When you sign up in the field of Cultural Studies in Education, headquartered in poststructuralist, this study aims at philosophical production of Michel Foucault's notions of discourse, truth and power as tools to undertake a cultural production and the other even in the context examined. Importantly, this debate does not want to assign a value-judgment to propaganda analysis. Its main intention is to confront the productive nature of discourse and educational advertising and its effects of meaning, among them the significance of differences as barriers to equality.
\end{abstract}

Keywords: Publicities' Discourse. Equality. Difference.

\footnotetext{
* Professora e Tutora da Universidade Aberta do Brasil, Universidade Federal de Santa Maria, Santa Maria, Rio Grande do Sul, Brasil.

** Professora Doutora da Universidade Federal de Santa Maria, Santa Maria, Rio Grande do Sul, Brasil.
} 


\section{Apresentação}

O cenário cultural utiliza diferentes espaços para criar, circular e validar sentidos. Um dos espaços que mais ganha visibilidade no contexto contemporâneo é a publicidade. Entre outras coisas, o discurso publicitário produz saberes e valores, circula comportamentos, constrói identidades. Enfim, ensina modos de ser e de viver. Nessa perspectiva, muito mais do que persuadir o/a consumidor/a a obter determinado produto, a publicidade é um espaço pedagógico. Portanto, trata-se uma forma de aprendizagem que interpela um elevado número de pessoas, já que a sociedade da mídia e da informação inventa estratégias que possam transpor barreiras de diferentes ordens - geográficas, culturais ou econômicas.

Nesse sentido, os variados produtos criados no e pelo discurso publicitário disseminam sentidos ao instituir realidades. São espaços de materialização de uma política da representação, visto que se constituem como dispositivos culturais que produzem significados. Trata-se, nesse registro, de uma pedagogia cultural. Silva (2001, p. 139) salienta que "Tal como a educação, as outras instâncias culturais também são pedagógicas, também ensinam alguma coisa". Daí a relevância da discussão sobre a produtividade dos artefatos midiáticos, neste caso, do discurso publicitário.

Nessa direção, o presente trabalho toma a publicidade em seu caráter pedagógico, entendimento este alinhado ao espaço de discussões empreendido pelos Estudos Culturais, de seguimento pós-estruturalista. Assim, pretende debater as possibilidades de significação da alteridade deficiente, entrelaçando noções como igualdade, diversidade e pedagogia cultural, a partir do anúncio selecionado como materialidade para esta análise. ${ }^{1}$

É importante salientar que, por se inscrever no referido campo investigativo, o propósito desta análise não é gerar evidências ou constituir um juízo de valor. Pelo contrário, seu potencial reside na tentativa de provocar interrogações que se constituam como insumo para outros questionamentos. Em outras palavras, exercitar o giro de inverter a direção do olhar, atentar para aquilo que está para além do cotidiano. Enfim, trilhar outros contornos na complexa cena pós-moderna, que traça de diferentes formas o lugar do outro na educação.

\section{Escolha teórico-metodológica}

Neste estudo, questões relativas à construção das identidades e à produtividade da linguagem midiática neste processo são acionadas para colocar em suspenso algumas narrativas mestras. Para tanto, os subsídios propostos pelo viés pós-estruturalista dos Estudos Culturais em Educação se apresenta como uma fértil caixa de ferramentas. Este espaço de discussões não é passível de uma definição essencial, em função do seu caráter cambiante e antidisciplinar. Entretanto, é oportuna a descrição esboçada por Silva (2001, p.139): 
Sob a ótica dos Estudos Culturais, todo conhecimento, na medida que se constitui num sistema de significação, é cultural. Além disso, como sistema de significação, todo conhecimento está estreitamente vinculado com relações de poder. É dessa perspectiva que os Estudos Culturais analisam instâncias e processos culturais tão diversos quanto museus, filmes, livros de ficção, turismo, ciência, televisão, publicidade, medicina, artes visuais, música.

Seguindo tal raciocínio, este território conceitual amplia as possibilidades de debate, incitando à análise crítica de textos culturais que estão fora dos domínios tradicionais de conhecimento, como é o caso do discurso publicitário foco desta pesquisa.

Sendo assim, o movimento teórico-político em questão constitui-se um campo de estudo marcado por um intenso desassossego, pela problematização de tudo o que é legitimado em regime de verdade. Dessa forma, não busca conhecer as significações globais e totalizantes que nomeiam a existência dos objetos ou sujeitos, mas entender as relações de poder que se articulam para criá-las.

Entre as noções estabelecidas por este movimento intelectual é a ampliação do que se chama de cultura, que adquire posição central nas análises produzidas. Para Silva (2001, p. 133-134),

\begin{abstract}
a cultura é um campo de produção de significados no qual diferentes grupos sociais, situados em posições diferenciais de poder, lutam pela imposição de seus significados à sociedade mais ampla [...]. A cultura é um campo onde se define não apenas a forma que o mundo deve ter, mas também a forma como as pessoas e os grupos devem ser. A cultura é um jogo de poder.
\end{abstract}

Nesse registro, a cultura vai para além das tradicionais compreensões de herança dos antepassados e essa perspectiva propõe uma virada culturalista, ou seja, o rompimento do binarismo cultura acadêmica versus cultura popular. Com isso, não há supremacia entre culturas ou entre "a cultura" e as "subculturas", já que a arena cultural é considerada um campo de tensão e permanente luta política, onde se travam embates em torno do processo social de significação.

Nessa lógica, quem é autorizado a falar sobre tal coisa ou pessoa, exerce o poder de atribuir sentido a ela, demarcando um regime de verdade. $O$ poder, nesse contexto, não é concentrado "nas mãos" de uma cultura dominante. Ao contrário, é concebido como transitório, produto e produtor das relações, o que se constitui numa das aproximações deste sistema teórico com a corrente filosófica de Michel Foucault. Ademais, tal conjunto de pesquisas utiliza a noção foucaultiana de discurso. Para este autor, discurso 
não é uma estreita superfície de contato, ou de confronto, entre uma realidade e uma língua, o intrincamento entre um léxico e uma experiência; [não é] um conjunto de signos (elementos significantes que remetem a conteúdos ou a representações), mas [...] práticas que formam sistematicamente os objetos de que falam. (FOUCAULT, 1995, p. 56)

Então, na perspectiva dos Estudos Culturais, a linguagem institui significados, inventa sujeitos, enfim, produz subjetividades. É neste sentido que o presente trabalho busca problematizar como são descritos, criados, exibidos, disseminados determinados significados sobre a identidade e a diferença em uma publicidade televisiva - bem como o atravessamento de questões como normalidade, sexualidade, gênero.

\section{A dinâmica de encobrirlenaltecer o outro}

Ao propor o espaço publicitário como um aparato cultural - e, nessa relação, pedagógico - faz-se necessário discorrer brevemente acerca dos entrecruzamentos históricos que tecem sua configuração. Jacks e Piedras (2005) argumentam que a partir da Revolução Industrial a área da publicidade tomou impulso. Nesta linha, Kellner (2002) cita os trabalhos de Postman, o qual ressalta a predominância de anúncios informativos, impressos ou verbalmente sedutores no século XIX e o uso de imagens a partir de 1890. Além disso, o autor afirma que o século XX, caracterizado pelo movimento da globalização neoliberal, consolidou a publicidade, especialmente a televisiva, como discurso público hegemônico, marcado pelo viés do consumismo. Assim, para ele, a mídia é, hoje, uma das mais importantes formas de produção cultural.

Entretanto, convém destacar o comentário de Escosteguy (2004, p. 146-

Discordando do entendimento dos meios de comunicação de massa como simples instrumentos de manipulação e controle da classe dirigente, os Estudos Culturais compreendem os produtos culturais como agentes de reprodução social, acentuando sua natureza complexa, dinâmica e ativa na construção da hegemonia.

Daí a importância do estudo das diferentes instâncias culturais, entre elas, a mídia, visto que os textos culturais são um lócus onde os significados culturais são negociados e disseminados. Para tanto, selecionam-se imagens, cores, contextos que, muito mais que persuadir, criam realidades. Dito de outra forma, assinalam-se regimes de verdade, os quais exercem o poder de representar as posições e papéis sociais dos sujeitos. De acordo com Silva (1999, p.15), é preciso "compreender [...] como funciona essa nova economia do afeto e do sentimento, na qual a apropriada utilização da mídia adquire um papel central". 
No contexto contemporâneo, em que o discurso da diversidade trafega com muita força na arena cultural, é oportuno problematizar a criação social de representações sobre a mesmidade e a alteridade, o normal e o anormal, a partir do investimento de poder exercido pelo discurso publicitário.

Para discutir algumas questões referentes à produção cultural da diferença, julgou-se conveniente utilizar um anúncio publicitário para servir de referência a esta breve problematização. Longe de pôr em pauta aqui o mérito do comercial, pensa-se que é relevante desnaturalizar como estes significados sobre a alteridade deficiente estão sendo produzidos e os efeitos de verdades que assumem na lógica contemporânea.

A propaganda eleita para análise foi veiculada até há pouco tempo, em caráter nacional, via televisão aberta. Trata-se de um anúncio que divulga uma instituição dedicada à reabilitação de crianças com necessidades especiais, conforme relatado a seguir.

O comercial tem início com a imagem de um menino de aproximadamente dez anos, loiro, utilizando muletas. Ele está em uma biblioteca e tenta usar seu instrumento de locomoção para pegar um livro em uma prateleira alta de uma das estantes. Ao notar a tentativa frustrada do garoto, uma menina de saia de pregas, aparentando um uniforme escolar, sobe a escada disponível e entrega-lhe o livro. Em seguida, ele visualiza outra garota e tem a mesma atitude, qual seja, simula a tentativa de pegar um livro numa prateleira alta, buscando a atenção de outra menina, também de saia, fazendo-a subir na escada. Ele ri, a menina entrega outro livro e balança a cabeça com um leve sorriso. Então, surge a seguinte frase: "Meninos são todos iguais. Todos. As diferenças acabam aqui". A seguir aparece o logotipo da instituição.

O primeiro aspecto que parece oportuno trazer ao debate é a forma como este anúncio, enquanto artefato cultural, produz a diferença como contrário de igualdade. Ao proclamar que as diferenças são passíveis de acabar, tal propaganda dissemina sentidos que remetem à totalidade, à homogeneização, à eliminação da outridade como pretensa garantia de igualdade. Assim, estabelece uma separação de igualdade e diferença em polos opostos.

Conforme Skliar (1999), diferença não é uma oposição à igualdade. O contrário de igualdade é desigualdade. Diferença e identidade fazem parte do mesmo jogo, estão interligadas. Isto porque a identidade é produzida a partir da diferença (Silva, 1999). A noção de diversidade, disseminada no contexto contemporâneo de globalização, acaba por encobrir as diferenças, como se elas pudessem ser toleradas, criando um inventivo acordo de igualdade. Dessa forma, o discurso da inclusão de todos na aldeia global, sob o manto do politicamente correto, torna-se recorrente, como se fosse possível mascarar ou eliminar as diferenças. 
Nesta direção, a perspectiva multicultural, que celebra a naturalização das diferenças a partir das noções de aceitação, tolerância, respeito, convivência seria mais uma tentativa de normalização das alteridades. Na tentativa de aproximar do polo convencionado normal aqueles que estão à margem, produzse a naturalização de seu posicionamento na tangente. Desta maneira, os ditos "normais" seriam os politicamente corretos ao permitir o ingresso, ainda que parcial, dos "outros deficientes" ao mundo dos "perfeitos", desconsiderando-se as correlações entre poder/saber imbricadas nesta relação binária.

O discurso publicitário do comercial, ao privilegiar a questão do gênero como baliza de igualdade, deixa de enfatizar outras, como a acessibilidade necessária à condição física específica do garoto, por exemplo. Não se está aqui julgando tal discurso, mas provocando o leitor para a os efeitos de sentidos que esta racionalidade produz. Parece ser muito mais confortável aos que estão na posição de normalidade narrá-lo como igual a partir do gênero e se manter inalterável no que se refere à diferença.

A própria ênfase no masculino - "Meninos são todos iguais. Todos" produz uma dupla supressão das diferenças. Neste caso, encobre tanto a discussão sobre a acessibilidade necessária à deficiência física, como as inúmeras formas de experenciar a masculinidade. A este respeito, é interessante notar que tal propaganda naturaliza a malandragem e o desejo de atenção da menina, ou melhor, de várias meninas, como algo inerente ao homem (heterossexual), mesmo que ainda criança.

E outra provocação: o sorriso das meninas, como que concordando com a atitude do garoto, produz tanto a noção de que se trata de algo "normal" aos meninos quanto uma atitude a ser perdoada em razão de se tratar de um deficiente, o recorrente discurso da tolerância. Nesse caso, parece haver uma oscilação, já que há momentos em que é mais conveniente enaltecer e tolerar o outro e há momentos em que é mais oportuno não o evidenciar, como se não houvesse traços da diferença.

A questão da tolerância, muito mais do que "acabar com o problema" da diferença, proclamando uma utópica harmonia, enaltece o quanto o diferente incomoda. Afinal, o tolerado ou tolerável é aquele que, de alguma forma, me incomoda, mas que eu tolero. Portanto, eu sou a referência do que é correto, eu não preciso sair da minha posição de normalidade. É sempre o outro que é o problema, não eu.

Talvez estas indagações não cruzem as discussões dos milhares de telespectadores do referido comercial, mas, certamente, os significados que ele circula ensinam a respeito da diferença, da igualdade, do homem, da mulher. Talvez o teor da propaganda fosse outro, se a criança deficiente em questão fosse uma menina. Daí emerge outra pergunta: Seria possível simplesmente trocar o menino e as duas meninas do anúncio original por uma menina deficiente e dois meninos? Provavelmente não. Afinal, meninos e meninas são narrados 
de forma diferente, ocupam lugares diferentes e isto não se deve às suas características biológicas, mas aos locais instituídos culturalmente para cada um.

Skliar (1999, p. 18) ressalta que "a alteridade resulta de uma produção histórica e linguística, da invenção desses Outros que não somos, em aparência, nós mesmos. Porém que utilizamos para podermos ser nós mesmos". Desta forma, a mesmidade e a alteridade não são o que são naturalmente, são produtos da cultura.

Assim, compreende-se que a diferença não é natural. Pelo contrário, a alteridade é uma construção social resultante de processos conflituosos e de significados negociados, em estreita conexão com o poder. Em outras palavras, o foco da discussão não está na deficiência, mas na produção social desta. A normalidade instituída culturalmente dá vozes às identidades, nomeando-as e posicionando-as nos limites ou à margem da norma.

Conforme Silva (2000, p. 100), "antes de tolerar, respeitar e admitir a diferença, é preciso explicar como ela é ativamente produzida". Assim, torna-se produtivo traçar um mapeamento da construção política do outro, para que se compreenda o processo de alterização dos sujeitos. Isso porque o cerne da questão não é o local que a diferença ocupa, mas a racionalidade que a posiciona ali.

\section{Notas para finalizar}

Se a alteridade é condição para a diferença e esta é produto de complexas tramas de poder/saber, então é preciso ampliar o debate, aprofundando os superficialismos com que são discutidas as questões que se referem às diferenças atualmente. Esta noção vai para além da "celebração da diversidade", já que propõe a problematização dos dispositivos culturais, que categorizam e nomeiam o outro fora da curva da normalidade.

Na perspectiva teórico-metodológica a que se filia este estudo, é possível verificar os movimentos discursivos que produzem a eliminação da diferença como garantia de igualdade. Para tanto, questões como gênero são enaltecidas e naturalizadas para encobrir o incômodo que a alteridade deficiente causa. Em outras palavras, torna-se mais confortável e menos perturbador à normalidade instituída enfatizar a masculinidade do que pisar o terreno desconhecido da deficiência. Com isso, naturalizam-se determinadas características daquela condição que se convencionou chamar de identidade heterossexual.

Contudo, há momentos em que se torna politicamente correto trazer o outro para perto, numa distância que permita tolerá-lo. Assim, a diferença é inscrita no campo da diversidade. De uma forma ou de outra, é possível averiguar a norma cumprindo seu papel de ordenamento, seja pela abolição ou pela aproximação da diferença. 
A partir da realização deste trabalho, pretende-se dar destaque a outras formas de olhar para as representações da normalidade e da anormalidade no espaço da mídia televisiva. Seu propósito não é apontar um caminho a seguir, pois se reconhece que o olhar do pesquisador é perpassado por suas histórias, emoldurado por discursos e interpelado por experiências - assim como de todos os sujeitos envolvidos de uma forma ou de outra com o texto a ser analisado (publicitários, contratantes, atores, telespectadores, leitores). Isso pressupõe uma múltipla gama de relações intersubjetivas e significados possíveis, o que vai além das intencionalidades e possibilidades deste estudo. Do contrário, correr-se-ia o risco de impor outra verdade científica, premissa que contraria sua matriz teórico-metodológica.

Ao compreender que as produções culturais subjetivam o homem e que a publicidade tem sido considerada um espaço privilegiado de circulação de discursos em na sociedade, novamente reitera-se que não se intenta de forma alguma tecer um juízo de valor sobre a instituição ou sobre os criadores deste comercial. O foco deste debate não é o estabelecimento em si, mas as representações sobre a alteridade implicadas em um de seus anúncios publicitários, bem como os efeitos que estes significados assumem no circuito contemporâneo.

\section{Referências}

ESCOSTEGUY, A.C. Estudos culturais: uma introdução. In: SILVA, T. T. O que é, afinal, estudos culturais? 3. ed. Belo Horizonte: Autêntica, 2004, p. 133223.

FOUCAULT, M. A arqueologia do saber. Tradução de Luiz Felipe Baeta Neves. 4. ed. Rio de Janeiro: Forense Universitária, 1995.

JACKS, Nilda; PIEDRAS, Elisa. A publicidade e o mundo social: uma articulação pela ótica dos estudos culturais. Contemporanea, v. 3, n. 2, p. 197-216, jul./dez. 2005. Disponível em: <http://www.contemporanea.poscom.ufba.br/ pdfjan2006/contemporanea_n3v2_x_elisa_jacks.pdf>. Acesso em: 28 jul. 2006.

KELLNER, D. Lendo imagens criticamente: em direção a uma pedagogia pósmoderna. In: SILVA, T. T. S. Alienígenas na sala de aula: uma introdução aos estudos culturais em educação. 4. ed. Petrópolis: Vozes, 2002, p. 159-189.

SILVA, T. T. A "nova" direita e as transformações na pedagogia da política e na política da pedagogia. In: GENTILI, P. A. A.; SILVA, T. T. (Org.). Neoliberalismo, qualidade total e educação: visões críticas. 7. ed. Petrópolis: Vozes, 1999, p. 9-29.

. A produção social da identidade e da diferença. In: SILVA, T. T. (Org.) Identidade e Diferença: a perspectiva dos estudos culturais. Petrópolis: Vozes, 2000, p. 73,102.

. Documentos de Identidade: uma introdução às teorias do currículo. 2. ed. Belo Horizonte: Autêntica, 2001. 
Outros domínios pedagógicos: a mídia ensinando sobre a mesmidade e a alteridade

SKLIAR, C. A invenção e a exclusão da alteridade deficiente a partir dos significados da normalidade. Tradução de Márcia Lise Lunardi. Educação \& Realidade, Porto Alegre, v. 24, n. 2, p. 15-32, jul./dez. 1999.

Notas

1 Trata-se de um comercial de uma associação que se dedica à reabilitação de crianças com deficiência, o qual será detalhado posteriormente.

\section{Correspondência}

Fernanda de Camargo Machado - Avenida Presidente Vargas, 547/303, CEP 97020-001, Bairro Patronato, Santa Maria - RS.

E-mail: nandadecm@yahoo.com.br

Recebido em 31 de maio de 2010

Aprovado em 08 de julho de 2010 
